ISSN: 2576-2141

\title{
Love, Fear, and Hope: Personal Coping Techniques of a Realistic yet Optimistic Daughter
}

\author{
Alyssa Sanabria ${ }^{1}$ \\ Florida Gulf Coast University, USA
}

\begin{abstract}
The purpose of this autoethnography is to explore my experience (the researcher) of coping with daily life after my mother's diagnosis of stage four metastatic breast cancer. Throughout this study, I will explore the experiences of myself and two other individuals whose mothers also have incurable advanced-stage cancer. I would like to know more about my own daily experiences and theirs in regard to how our daily lives have been impacted since the initial diagnosis. I would also like to explore the reality of living with the knowledge of a daunting inevitable loss, without a miracle. Through this study, the following themes emerged from the thick, rich data description: appreciation, fear, and coping skills.
\end{abstract}

KEYWORDS: Autoethnography, Breast Cancer, Grief, Incurable Cancer, Mother-daughter Relationship, Personal Coping Techniques.

In life we never choose grief, rather it chooses us. While we cannot control the time or manner in which grief will come to claim us, we can however actively choose how to cope with it (Greenspan, 2003). Grief does not need to be rushed. We can let it be while embracing and "honoring it in the way that we were called to" (Greenspan, 2003, p. 94). My mother wanted to allow me to remain optimistic in a dark time that felt hopeless and cold. She was a loving and caring woman who would do anything to protect her children from impending pain. I knew her eyes though.-, I could see the fear; I could see the concern that she was desperately attempting to conceal. Perhaps that fear is precisely what guided my mother to request me to come with her to her initial oncology appointment.

It was October 17, 2018; we arrived at the oncology office knowing already in our hearts something was wrong. My mom was a nurse by trade, and a week before the appointment she received the scan results that looked anything but promising. We had been going in and out of the hospital since January trying to find out why her liver levels were "through the ceiling" and why she was in so much pain without an apparent cause. As if the pain was not enough of an indication for concern, the ways she was changing physically right before our eyes definitely was. She was thinner than she had ever been, and her clothes just hung on her frame. We arrived at the facility in Miami and walked arm in arm as my father parked the car. We knew the appointment would reveal exactly what we were dealing with, but no one dared to speak the dreaded word "cancer". At the front desk, as she signed in, I took a few candid photos of her that I planned to use in a scrapbook to document her fight, journey, and overcoming. This was evidence of my overwhelming hope and optimism. I do not remember how long it took for us to be called back, all I remember was the countless women of all ages walking out bald and looking sick and tired. This sight made me so sad, I wondered, how did we get here? I

${ }^{1}$ Corresponding Author E-mail: alsanabria@fgcu.edu 
contemplated if this was real? Her name was called, and we were placed into a room to wait, my mind began to race as we watched the door endlessly for the doctor to enter.

My mom sat in a chair across from my father and me. No one spoke we all just waited, controlling our breathing and trying to get past this feeling of impending doom. The oncologist entered and while she was warm and friendly, she wasted no time getting straight to the point. My mom did have cancer; however, it was far worse than we imagined. It was stage 4 metastatic breast cancer that had already spread to her liver, hips, and spine. We were given no optimistic treatment plan yet rather a palliative plan and the options we could try to prolong her life. Some of these options were pills that helped to keep cancer from spreading, chemotherapy, radiation, and spine surgery to reconstruct bone damage. As if this all wasn't painful enough we were informed that there was no cure besides a divine intervention from the almighty above, as well as the textbook life expectancy was 2 years. My father and I just stared at each other, but my mom's reaction was not what we expected, mom was asking about treatment options and how could she fight. The sadness in her eyes told me everything I needed to know. My mom was determined to give this everything she had even if there was no cure. Like many others, she believed she could be the one who defied all odds, and as crazy as it sounds, this was the moment a realistic and optimistic daughter was born because I too believed this. I refused to begin the grieving process and was determined to be a pillar of optimism. Because I recently had begun my doctoral journey, I decided to use my newfound research skills to find cases that proved a miracle was possible.

As the daughter of the strongest and most optimistic mother, I became very protective and proactive within my daily life. I asked as many questions as possible while aggressively digging into literature about treatments and survival rates. This became almost a sick daily process of waking up and researching to find exactly how long I had left with my mom. Then, refuting the findings mentally based on one success story. My emotions ran the continuum from denial, which turned into anger, then graduated to sadness. I was counting down the hours until I was alone in the house so I could hyperventilate, cry, and grieve an individual that was still very much alive and fighting, an individual who I could call and talk to for hours.

My readings and research-informed my attitude towards dealing with the difficulty and pain of mourning because I had to get ahead of the inevitable. At that moment I did not realize it but I was in the beginning stages of the grieving process. The thought of losing a loved one shatters our understanding of ourselves, our individual lives, and our futures. Grieving is a process that allows an individual to begin to reconstruct the meaning of their lives (Neimeyer, 2010). My expectations and assumptions about my life were shattered and I was scrambling to find a way to pick up the pieces and feel remotely whole again. Hence, I started writing as a way to process the pain of the known unknown.

At the beginning of my mother's fight, writing provided a path towards empowerment, hopefulness, and reflexivity. The night before my wedding- instead of writing my vows- I stayed up all night writing this autoethnography while watching my mom sleep in my guest bedroom. I remember feeling a release of pain and fear with each word I wrote, all the while hoping that the words about overcoming and optimism would be our family's fate. After her passing, amidst the grief, shock, pain, and anguish I pondered ways to use my grief and coping strategies to impact others who may also be struggling. Although my mother has joined the statistical number of the countless women who have fought this tumultuous battle, her life and this painful experience cannot be viewed as another sad ending. My goal eventually became to capture the essence of my mother in the belief that our family's story will support others navigating grief. Writing allowed me to become intimate with difficult thoughts, unveil my emotions, and expose a cultural web to which I felt deeply connected. My investment within this project is high and my intention is simple: help someone else who may be struggling with the darkness that loss can cause. 
Our mother was 49 years young when she died. While physically she is not here, through telling our story, her charismatic personality and passion for life will continue to impact others and serve as a light for those struggling with fear, pain, and the grief that incurable cancer brings into the lives of countless families every day. Spry (2012) indicated a similar process after becoming frustrated with the dominant cultural narratives of grief and personal writing. There was a moment of giving in to the rupture and allowing herself to fall apart and see the pieces. Using her own experiences of "the multiplicity and partiality of knowledge become deeply embodied" within an autoethnographic state (Spry, 2012, p. 227).

\section{Purpose of the Study}

The purpose of this autoethnography is to examine my experience of coping with daily life after my mother's diagnosis with stage four metastatic breast cancer. My research questions were: In what ways did my mother's diagnosis of stage four cancer affect/impact my daily life? What outside factors influenced my viewpoint of how to cope with grief and loss? I explored these questions by examining a cultural web of other individuals struggling with grief and the inevitable loss of a mother to cancer and by analyzing our experiences, feelings, and recollections. My hope is that our stories and experiences will support others navigating grief and loss.

\section{Literature Review}

Breast cancer claims the lives of approximately 43,000 women in the United States yearly, leaving 55,000 young, adolescent, and young adult children without a mother (Phillips, 2015). Breast cancer has become more normalized within American society., One example of normalization are media advertisement campaigns regarding treatments for cancers; however, the women most likely to die from incurable breast cancer have gotten the least amount of attention (Pickert, 2019). Incurable cases such as advanced stages, metastatic, or recurrent disease are increasing yearly (Phillips \& Lewis, 2015). The effects of these life-threatening illnesses can be viewed as "traumatic for both the person diagnosed and their immediate family members" (Garrard et al., 2017, p. 3561). This finding is powerful; however, the use of the term traumatic feels understated. Within my experience, the feeling was more along the lines of lifealtering and agonizing. Phillips (2015) explained this pain very bluntly by stating that cancer interrupts the family's life trajectory, simple daily life tasks seem insurmountable, and time seems to freeze or move in slow motion.

Maternal breast cancer has been shown to have a significant impact on the well-being of children (Almulla \& Lewis, 2020). Davey et al. (2005) stated that women and girls whose mothers had breast cancer were the most significantly distressed; their findings validated my feelings of anguish. I remember thinking at one point why am I coming emotionally unglued meanwhile my male family members are living life with so much hope. Stiffler et al. (2008) explored through a phenomenological approach the experience of being parented when mothers are diagnosed with breast cancer. During the open-ended interviews, information was divulged that revealed the majority of daughters felt their mothers were incapable of dying. They posited daughters struggled with the intrusive thoughts of their mother being incapable of dying, while still being supportive, and struggling to find reactions that were acceptable to themselves and also to their mothers (Stiffler et al., 2008). Their findings took my breath away because, as absurd as it sounds, this was exactly how I felt. I wondered who I would call every day and how I would fill the void the potential loss of my mother would leave? Stiffler et al. (2008) painted a vivid picture of the stages the daughters felt after diagnosis: A world turned upside down, stop the intrusion, mom can't die, a hole where mom used to be/filling this hole, being there for mom, managing reactions, and guarded relief. These stages were so accurate to my experience 
and created a feeling of solidarity: just knowing that other women were experiencing this uncanny compilation of emotions brought me a small sense of inner peace. These feelings were validated by Fisher et al. (2016) who uncovered that mother-daughter communication is central to adjustment however coping is not as simple as just being open. While informative, this still left me with a deep drive to understand why male reactions were less emotional and focused on the positives. This was deeply important for me to understand because as the only girl in my family I felt out of place and uncontrolled with my emotions. As I read further I discovered some clues in the findings of Davey et al. (2005). Their research revealed that sons and fathers may have difficulty adjusting to illness and hence avoid communication and hide their true feelings from the family. Meanwhile, daughters traditionally support their mothers during the illness which can also lead to a myriad of effects from withdrawal from family, friends, and even their mother at times due to fear, anger, and resentment (Davey et al., 2005).

All in all, the literature painted the picture of how cancer disrupts families while leaving the children of the mother feeling as though they have "the weight of the world on their shoulders" (Phillips \& Lewis, 2015, p. 854). This helpless feeling can cause different reactions between male and female offspring and hence different genders may have different experiences (Davey et al., 2005). Also, another component appears to be that age can make a difference within the experience and affects the lives of younger children who need structure and routine while adolescent and young adult children can better equip themselves with coping strategies (Garrard \& Fennell, 2017). Also, young adult children often take on a caregiver role. This is significant because young adulthood is often when many are preoccupied with considerable personal change and life events. Similarly, this concept of being a caregiver was a role I as well as my 23-year-old brother assumed during such a pivot point within our young adulthood. I was preparing to get married and literally had just begun my doctoral program; my brother was about to graduate and start his career and move out of the dorm into his first apartment. Goldblatt et al. (2018) describes that being a caregiver allows them the ability to put their life tasks on hold temporarily to allow themselves to be present in the here and now, despite their young age. While this seems like a heavy burden, it is one that is more common than not. While as a family we shared this heavy burden, our father made the ultimate sacrifice and became our mom's full-time caregiver. All of this suddenness and ambiguity experienced from a diagnosis of cancer can leave the family feeling like the life they knew had disappeared and they were left wondering through the dark trying to find ways to react (Holst-Hansson et al., 2017). Research indicates that no two people will cope with the same diagnosis the same way hence the "just have to deal with it" mentality is not the answer to all cancer diagnoses (Phillips, 2015, p. 1060). While the literature offered me some insight and assurances that my feelings and reactions were within "normal limits" of others facing the consequences of a cancer diagnosis; the harsh reality of becoming a statistic was still overwhelming and research offer no soothing remedy.

In an effort to make sense of my experience, I turned to writing, so I could examine my coping mechanisms and the ways I "just dealt with this daunting reality". This idea of "just dealing with it" looked different daily;; some days I would cry, other days I would spend all day on the phone with my mom never wanting to hang up, and other days I would write poems or positive messages to her. Through this daily process, I began to realize my positionality had changed., I was no longer a teacher and doctoral student first;; I was a daughter who had a mother with stage four cancer. After admitting this gripping positionality, I was able to realize I had two individuals within my cultural web who also were the children of mothers with a textbook-defined "incurable" cancer diagnosis:- my younger 23-year-old brother and my mother-in-law who had stage four cancer herself that is currently in remission, however, her mother has incurable cancer. What could this web of individuals teach me about myself? How could we support each other? What could our stories teach us about being survivors? Autoethnography provided a platform for me to document and reflect on my experiences, the 
experiences of others, and how they impacted our relationships, perceptions of reality, and coping mechanisms. In this story, special attention will be paid to my attitude toward the diagnosis, how it changed over time, what factors impacted this change, and how my attitude impacted my ability to cope with my daily life and the daunting reality of living with loss.

\section{Theoretical Framework}

My theoretical framework reflects a social constructivist lens because I seek to construct my own knowledge as a path towards a deeper understanding of in what ways I coped with grief and began to understand the impending realities. Within the social constructivist framework, we are able to construct multiple realities through our lived experiences and interactions with others (Creswell, 2018). I took inspiration from the work of Charmaz (2005, 2006, 2014) who advocates for a perspective that includes multiple realities as well as the complexities of views and actions from experiences. This interpretive approach to qualitative research allowed me to learn more about the experience embedded within along with hidden networks, and relationships. Through this experience, I was able to understand and become open to my own self-transformation experiences. With a profound understanding of my cultural web of fellow children experiencing the pain of having a mother with incurable cancer, I was able to bring a deeper understanding of the grieving process. This revealed transformation through grief is indeed possible by maintaining open-mindedness and exploration of shared stories and experiences. Recognizing the impact of grief and loss and how it affected my actions, thought processes, and interactions with others led me to transform my mind, thought process, and spirit. Social constructivism opens the door for transformation to occur and permeate one's mindset and became a healthy coping mechanism to understand and express emotional trauma.

\section{Methodology}

I chose an autoethnographic methodology because "autoethnography is the idea of multiple layers of consciousness, the vulnerable self, the coherent self, critiquing the self in social contexts, the subversion of dominant discourses, and the evocative potential" (Creswell, 2018 , p. 312). Autoethnography is defined as a narrative form of writing recorded by the individuals who are the subject of study (Creswell, 2018). Chang (2008) allows for the understanding that all and any aspects of life can become subjects of autoethnography. Chang (2008) also advocates for the exploration of a cultural web of others in order to further understand one's positionality.

This autoethnography is grounded within the philosophical concept of Postmodernism. Postmodernism focuses on the ability "to change ways of thinking" (Creswell, 2018, p. 34) which supports the social-constructivist lens of transformation. Autoethnography is built upon this theoretical assumption and Chang (2008), is known as the autoethnographic theorist who best followed this stance. Chang's (2008) autoethnographic style is to combine cultural analysis and interpretation with narrative details to explore the understanding underlying my daily experiences. For this study, the cultural web was two other individuals who, at the time of this writing had a mother with a stage four incurable cancer diagnosis. These individuals were selected because since they were going through the same experience with their mothers hence they offered a unique perspective. I also had a personal relationship with both participants which allowed them to feel comfortable discussing components of their experiences that might have been challenging to talk about. Autoethnography offered me the opportunity to open myself up as a researcher and truly begin to explore my perspective based on my past, present, and future and the lives of others around me. I was able to develop and nurture my 
understanding through my personal thoughts as well as through the perspectives of those within my cultural web.

The key components within this autoethnography are the use of personal writing, past/present experiences, and memories. The data was gathered from personal memory, journal entries, and interviews with other adult children facing the loss of a parent because of cancer. "Personal memory is a building block of autoethnography because the past gives a context to the present self and memory opens a door to the richness of the past" (Chang, 2008, p. 71).

The participants within my "cultural web" are both individuals I cherish and go to often for advice and assistance with regards to this subject as they are both experiencing the same pain of having a mother with incurable cancer. Both participants were interviewed then asked to reflect on their thoughts and report them via reflective entries. My relationship with Participant $S$ is that he is my 23-year-old brother hence we shared a mother with stage four metastatic breast cancer. My relationship with Participant $M$ is she is my mother-in-law and her mother has incurable cancer and is my grandmother-in-law. Participant $\mathrm{M}$ also had stage four cancer and was given grim hopes two separate times however beat the odds and has been in remission for 12 years and counting. Participant M's perspective would be rather interesting as she has lived through two recurrences and now is assisting her mother with this monstrous disease that is ripping through her family. By interviewing individuals within my direct cultural web, I was able to explore and gain insight into the complexities and daily struggles of individuals like myself struggling currently with this battle. Throughout the process, I kept an open mind to understand my feeling as well as how they related to the experiences of others. I openly admit my closeness to the topic is a limitation and implemented member checking and triangulation to minimize bias.

This concept of autoethnography involves a brief component of autobiographic elements (Creswell, 2018). I am a twenty-seven-year-old young lady, the oldest child in my family, and the first child of three to graduate college and work/live independently. I am married and at the time this research began I had no children; however currently I have an 11month-old daughter. My first love has always been school and my work as a special educator. I strive to use school as a wonderful distractor for any struggle within my life. My love of schooling somehow led me to become an educator which I have been for 7 years now. This is the same love that drove me to start a doctoral program. I began the program shortly before my life-altering news in October of 2018. This is when I realized that school was my muse, I used to drown myself in writing and reading research as my coping mechanism of escaping my sickening realities. I hated that everyone wondered if I would drop out because of my mother's diagnosis. But rather than crumble, I used school as a way to make my mother proud plus, in my mind, I felt she would beat the odds because she is the strongest woman I have ever known. I recognize my view of cancer, cures, and its impact is biased and impacted my ability to be balanced during this investigation.

\section{Research Questions}

The research questions were devised to help deepen the exploration of the grief process. The overarching research questions were posed to guide me while examining my experiences and the experiences of those within my immediate cultural web to support individuals currently experiencing the grieving process. The following are the two research questions:

1. In what ways did my mother's diagnosis of stage four cancer pose a challenge to my daily life?

2. What outside factors influenced my viewpoint of how to cope with grief and loss? 


\section{Data Collection and Analysis}

Within qualitative research, it is traditional to collect multiple data sources (Creswell, 2018). Autoethnography requires thick rich data that emerge when participants are able to tell their life experiences and internal thoughts. In an effort to fully explore and understand my daily experience of living within this reality of grief and loss, I examined my experiences through writing, reflection, and analysis. I also used interview transcripts and reflective writing from my brother and mother-in-law. Both methods of data collection circle back to the purpose of exploring my daily experience of living within this reality of having a mother with incurable cancer and how it impacted me as well as how I coped with daily life after my mother was diagnosed.

I transcribed the interviews by hand, no computer software was utilized for transcription. I then provided the transcripts to the corresponding participant and received all corrections and made the necessary edits. I used constant comparative content analysis and embraced Hodder's (2003) belief that meaning does not reside in the text but in the writing and reading of it. Following Chang's (2008) advice, I read, categorized, and probed in order to comprehend how our behaviors, experiences, and perceptions were interrelated and how we coped with grief and loss. I shifted my attention back and forth between my participants' experiences and my own in an iterative process beginning with simply reading the data, then moved on to "fracturing" or coding, then rearranging the codes into categories and eventually broad themes. I looked for connections between my personal data and that of my participants. My goal was to find the interrelationships between the ways we coped, felt, transformed, and made meaning of grief and loss. By identifying these themes, we could provide others with an insight into the experience of dealing with such a harrowing reality.

Creswell (2018) describes trustworthiness or verisimilitude as a "study, in which the writer seems real and alive, transports the reader directly into the world of study" (p. 328); this is the concept of ensuring that your writing is trustworthy and relevant to your audience. Within this autoethnographic study, I utilized a triangulation of interviews, participants' reflective entries, and my own diary entries/personal experiences to ensure concise and cohesive research. This triangulation required that I search for confirming evidence to develop and understand the overall essence of our experiences coping with illness, grief, and loss. Throughout the process, I kept an open mind to understand my feelings as well as how they related to the experiences of others. Keeping an open mind and sharing stories and experiences from times of struggle allowed me to process what I was feeling. By sharing my story, I truly hope to impact others' understanding and processing of grief and pain. Finally, member checking was utilized to ensure accuracy and thoroughness (Creswell, 2018).

\section{Findings}

When trying to organize and understand the data it was naturally difficult to keep my emotions in check for this process is not just a study, it is my life and the lives of my brothers and my mother-in-law. On a daily basis, we wake up and feel this immense weight that takes over our minds. As I wrote this sentence, I was sitting in a room at 3:13 in the morning starring at the beautiful woman I called my mom. It is like I always want to be around her and enjoy her as it gives me a sense of peace and calm. I always want her to know how grateful I am for all she has taught me however I cannot reveal to her my internalized fears. This leads me to the theme of appreciation. Now, remember the question at hand is in what ways did my mother's diagnosis of stage four cancer affect/impact my daily life? Appreciation is the answer to this question and it's the motivation for how I complete my days.

In life we are not always grateful, sometimes we covet others and think how things could be better. It is not until something comes and rocks our entire world that we learn to appreciate 
what we have. Now I look at photos of my mom and think of "all the times I took her for granted or I watched others just brush their mothers off and think to myself if they only knew what it was like to fear losing; wondering if today is the day she leaves us forever." Appreciation is the only way I can be positive. Participant S said "it causes me to not take things or people for granted. Everyone faces things in their life, when it gets more personal and closer to home it shows you to not be ungrateful" (Participant S, 2019). Life seems to just stop; every moment is played in slow motion and you appreciate the smallest things. In my journal reflection, I recalled, "my mom left today and I sat in my room and cried for three hours just wondering if today was the last day I would see her, every time she leaves I want to run after her and tell her what an amazing woman she is and how grateful and appreciative I am of her." Yet with appreciation comes fear, the fear that our mothers wouldn't be there.

This fear can begin to consume your life and thoughts. Fear made us feel like we were dying in little pieces. I would turn on the radio and hear a song about missing someone and just cry. Participant S said that looking at our mother's back caused fear because "seeing her hunched over and in pain was terrifying" and reminded him that the "cancer was spreading to her back and beyond" (Participant S, 2019). Changes in our mother's bodies brought on feelings of fear and reminded us of the reality of loss. Seeing someone you love slowly lose the ability to walk and become super forgetful is scary especially when they are still young. Although we shared similar perceptions of fear as individuals, we dealt with them differently.

I would wait till I was alone and sit in my bathroom and cry. When I say cry, I mean bawl and scream and hyperventilate. I just felt this sickening fear that overwhelmed me. I turned to writing in hopes it would help with abating the fear and, needless to say, I filled books. The most powerful piece I wrote was entitled "my mirror." This poem described that the fear of losing my mom was so immense that I hated to look in the mirror because I look just like my mother and when I looked at myself I saw her. I wondered how in the world I would look at myself knowing all I see is her. I had to deal with the truth that my new reality was fear and fear would always be there, but I cannot live the remainder of my days in fear.

Participant M provided insight to dealing with this daily fear "well me being a Christian and having hope in reuniting again, even though it is going to be hard. We are here temporarily so at one point we have to go, for all we know I can go before she does. There is no saying when it is going to happen, and I try not to keep it in my daily thoughts" (Participant M, 2019). She held fear of loss but her faith in the Lord sustained her and did not consume her in the same way it did me. Her realization that fear could "consume the living" helped me realize I could not live with fear for the remainder of my life.

Today, we often hear the pundits ask "how do you balance your life?" This idea of creating balance as a way of escape the constant state of anxiety that appears to swirl all around us leads me into the third and final theme of coping skills. To deal with our harsh, daunting reality and combat fear, each of us realized we needed to create balance in our lives. The balance had the possibility of creating ways of escaping the reality of grief and loss. One way we coped was to try to normalize life and live each day as it evolved. My brother chose to balance and escape using "sleep and trying to not think about it. Just trying to zone out" (Participant S, 2019). My mother-in-law turned to "crocheting or shopping for kitchen items" (Participant M, 2019). I related to both of these approaches to coping; however, I chose to stay busy. I noticed whenever I had downtime, I threw myself a pity party for one and one is a lonely number. I kept busy with work, working out, school, and my sorority. I came home to eat and sleep. Although we chose different paths, escape wasn't easy and perhaps unhealthy; but escape became a way to fight fear and combat the ongoing feelings of grief and impending doom.

This section served as an introduction to the three themes uncovered throughout this process: appreciation, fear, and coping skills. All three participants spoke of the immense appreciation this disease sparked within them for their mothers, they also spoke of the fear of losing such a marvelous person, and finally, they all highlighted the way they attempted to 
continuously cope. The themes are listed in the order of how they were uncovered within the data analysis process.

\section{Appreciation}

Within the literature, there is mention of children coping with a mother's illness (Garrard et al., 2017) however little in the literature highlights the specific aspect of appreciation. While there was a gap in the literature detailing appreciation as a way of processing grief, it certainly served a valid purpose in dealing with daily life for both participants as well as myself. I remember my mindset was, I am grateful for all the moments we have together and I tried to enjoy every day and live as happy as we could. Participant S (2019) stated that the diagnosis "caused me to not take things or people for granted. Everyone faces things in their life, when it gets more personal and closer to home it shows you to not be ungrateful." This humbling of one's self to appreciate what you have is a commonality that strikes a strong chord with me as well. Within my journal, I mentioned the following "appreciation of the time and sacredness of the bond is everlasting through the pain of the possibility of losing the one who brought you into existence." This appreciation is coupled with the idea that fear is still imminent and almost omnipotent. The theme of appreciation relates to the aim of this autoethnography by serving as a way to cope. Being appreciative of life and appreciating the individual and time remaining allows for a sense of comfort. Often time people do not realize and appreciate people until they are gone so utilizing the spirit of appreciation can serve as a healthy way to manage the coping process. Much of the literature reveals the long-term effects of loss and the significant impact loss has on the well-being of the adult children and children alike (Almulla \& Lewis, 2020) yet appreciation lends itself to be a new finding within coping skills. Allowing yourself to appreciate someone for all that they offer to your life and embracing them while they are still present allows for you to bond and be thankful for the time. Through this appreciation, you being to cope with not wanting them to be in a state of misery and pain rather capturing and appreciating them for all that they are before, during, and after the illness.

\section{Fear}

Stiffler et al. (2008) explored the fact that daughters felt like their mothers were incapable of dying. This concept that "mom can't die" and the fear of what might happen if you lose your mother was evident within the literature as well as among the participants. For some individuals, the concept of mom can't die hits so much deeper because their mother is their lifeline, for me and my brothers, this was our mindset. Our mom was the glue that bonded our family together, she was who we called whenever we needed anything. When I reached early adulthood, our relationship evolved into a close best friend bond and we talked nearly all day every day.

"The most difficult part emotionally is knowing that there is no cure and just hoping that she will last years, I have to take it a day at a time" (Participant M, 2019). The literature was clear that the fear comes from the unknown and children's need to control something much larger than themselves (Almulla \& Lewis, 2020). As I navigated between fear and hope I created the following analogy to explain how I constantly felt: In life, we all have an invisible clock above our head with the time that our day stops; however, when someone is sick it, seems like this clock is now visible and counting down quickly. Watching the progression of the illness made me want to shake the clock and try to stop time. But unfortunately, I couldn't. I also grappled with all that I would be willing to give up if somehow my mother could just be rid of this horrible illness, but that did not work either. However, the scariest part of this journey was I never knew the day or the time that the clock would run out. While my mother-in-law and I 
vacillated between fear and hope, my brother continued to be a lighthouse in our family, remaining hopeful through the roller coaster of emotions. While I knew he struggled in silence, because I saw the pain in his eyes, when he spoke to me, our mom, our little brother, or any family members he would always emphasize how strong our mother was and "that she would beat this" (Participant S, 2019). I never saw my brother show signs of true fear until the day he and I kissed our mother goodbye, not knowing this would be our last time. He was so strong and hopeful during the visit, pleading with our beautiful mom to keep her fight alive and that he would handle everything. However, as soon as we exited the doors, I saw the fear in his eyes and he joined me in the land of tears. That day from the time we entered the room, till the time we got home I could not stop sobbing, I normally could keep it together but I fell weak. It was like my fears were mocking me and taunting me, I felt haunted and still, my mother fought for almost another two weeks. To this day I remain so amazed by the strength my brothers and father portrayed in a time when I felt hopeless; I knew they were fearful on the inside because they told me but always upheld a brave face. They did not showcase fear until it became apparent the situation was grim (Davey et al., 2005). For others sharing this life experience, the realization that fear and hope resided side by side may help them work through these two emotions in a more balanced way. Fear of the unknown will consume life unless you develop coping skills and ways to manage it. Realizing that life cannot be altered and while you can appreciate and love a person you have to begin examining ways to effectively cope with the daunting realities.

\section{Coping Skills}

Whether it is "crocheting or shopping" (Participant M, 2019) or "listening to her favorite songs, zoning out, or sleeping" (Participant S, 2019) personal coping skills were necessary and vital to our ability to function in daily society. In the early stages of my mother's diagnosis, I did not have coping strategies and when alone I would break down for hours and cry. It is evident that healthy coping skills are the only way to face this daunting and terrifying reality (Khanjari \& Mianji, 2020). The literature mentions age can make a difference in one's ability to cope. Younger children need structure and routine while older and adult offspring can better equip themselves with coping strategies (Garrard \& Fennell, 2017). Our experiences indicated that structure can be the saving grace for all members of the family regardless of their age. This was evidenced by examining how my father, brother, and I kept a structure and sense of normality that allowed for my now 10-year-old brother to function and exist even though his life was anything but normal. The research indicates that no two people will cope with the same diagnosis the same way hence the "just have to deal with it" mentality is not the answer to all cancer diagnoses (Phillips, 2015, p. 1060). I realized this will never be easy or normal ever again (Phillips, 2015), we chose a myriad of ways such as school, shopping, and music to cope and challenge our lives into action. This concept of self-coping was also reinforced by those within my cultural web who use personal coping as a way to quiet the mind and silently begin to grieve. My writing and being able to share this experience is a coping skill and a way to show the world that I can use my pain to help educate and improve others. It's a testament to the strong lovely lady who raised me. Khanjari \& Mianji (2020) found that coping skills training led to improvement in quality of life for girls and women whose mothers had breast cancer. Coping skills allow those struggling in pain to find a way to make life bearable. Coping skills also helped us adjust to the reality our lives would never be easy or normal again. We had to shift our trajectory because incurable cancer is as "traumatic for both the person diagnosed and their immediate family members" (Garrard et al., 2017, p. 3561). Finding the healthiest ways to increase our quality of life while dealing with fear, anxiety, and pain can be accomplished through coping skills. 


\section{Discussion}

Throughout this study, I examined how I coped with daily life during my mother's illness and after her death. I specifically explored the impact of this experience on my daily life to assist others in understanding and dealing with this life-altering situation. Although the review of literature I presented included numerous studies on the impact of cancer on children or teens (Davey et al., 2005; Garrard et al., 2017; Phillips, 2015; Phillips \& Lewis, 2015; Stiffler et al., 2008); there exists a scarcity of qualitative studies, especially autoethnographies examining young adults' daily experience living with a mother with stage four cancer. Therefore, I would like to share my story to impact others as well as to add to the literature on living with the daunting reality of embracing the impending inevitabilities while remaining hopeful, appreciative, optimistic, and sane. While all present literature highlighted the factors that loss leaves a new normal that will never be the same and how dynamics family change; none especially looked into the daily experience of a young adult losing their mother from an autoethnographic perspective. Hence this prompted the need to give a voice to the unheard voices of all those suffering and struggling in silence, for all those who smile and say encouraging things yet behind closed doors cry and feel like your heart was ripped out and describe the essence of this daily life coping with grief and pain. In this section, I provided a brief discussion of the three themes in relation to the review of literature.

\section{Conclusion/Implications}

In conclusion my findings of embracing appreciation, acknowledging fear, and find the personal coping skills that work for each person support the literature regarding coping with grief and loss (Khanjari \& Mianji, 2020; Kentor \& Kaplow, 2020). But, more importantly, the implications of my story on others will be:

Through the pain continue to find the points to reflect and show appreciation for the one who you fear losing.

Do not lose yourself in the fear but instead welcome the emotion, observe how it makes you feel, and release the pain through healthy personal coping skills.

Through my daily experiences, not a second has passed in which my life has not been affected since my mother's initial diagnosis. The day we lost her is still engrained within my mind. Pulling onto our street all blocked off, running as fast as I could pass the cops and ambulances trying to get to her. The look on my dad and younger brother's faces when I entered the room, the smell of the hospital supplies, and the fleet of emergency service workers surrounding and invading our home preventing me from seeing her. The lack of empathy for our loss and the insensitive questioning and prodding. The visual from this day, the pain of seeing the one you love lying in a familiar space but gone and never getting to say I love you one last time is depilating. Death is not pretty, it is not like the movies; it is ugly and mentally traumatizing. These memories haunt me daily and cause me to feel a deep sense of agony. For so long I lived in a land of oblivion and optimism, searching endlessly for a miracle or a study with hopeful outcome. I realized through this process that by embracing reality you can impact your mindset and begin to shift to the grieving process. Waiting until the unexpected day when the imaginary clock stops leaves you feeling like you are in a fog. It creates a sense of withdrawal and denial. Allowing yourself to feel the emotions throughout the process and appreciate and love the individual allowing you to begin the grieving process. Fear will always be present; however, you have the power to embrace the emotion and handle it head-on. The ultimate goal of this study was to pour my heart and mind out and show that autoethnographic methods can be therapeutic and impactful. I hope that this autoethnography of my life can impact someone struggling with the daunting and reality of inevitable loss without a miracle. Remember to embrace fear even though it is scary, show appreciation, and cope in a healthy 
way. Life may never be the same but through coping, you are able to live in a way to bring honor to a legacy lost.

\section{Dedication}

The publication of this piece is dedicated to my mom Lorie Sinclair, who lost her courageous fight to metastatic breast cancer on October 9, 2020. This piece was written in a time of hope and reflection. I hope that those who read this autoethnography will see the power of this qualitative method. It allows me as the author to become intimate with hard thoughts and produce literary art using emotions and a cultural web. My mother has joined the multitude of other women who have fought this battle however in honor of her fight and courageous attitude this piece was possible. I started to write this piece when my mother was one year into her battle with cancer and the months leading up to my wedding. I remember sitting up writing watching her sleeping and just hoping that the words I wrote about hope and overcoming would be our fate. While we only had her for two years after this diagnosis, I realized the privilege I had to know her for my 27 years of life. Lorie Sinclair was 49 years young on October 9, 2020. While physically she is not here with our family, her photo is on my desk and she will forever be the passion behind my words. To my brothers, I want you both to know this piece showcases our mom in the way the world should always see her, as a one of a kind and a changemaker. She loved us all so dearly and was so proud of all three of us. Remember we have to make her proud always and continue to be the strong three she raised us to be. To my father, you have held the role of caregiver and now a single parent. While this is hard you do an amazing job of taking on the role of mom and dad now. I dedicate this piece to our mother and all that we are thanks to her. If she did not work so hard to provide my brothers and me with the educational opportunities we were given, I would not be enrolled within my doctoral program and writing at all. Many times, I would call her crying and try to give up but she always bragged that "her daughter was going to be a doctor". So, with those words ingrained in my head, every time I doubt myself on this long doctoral journey, I know that I have to make it because she spoke it! May this piece serve as a light for those who are struggling, remember to write in your fearful times because the product might become a powerful memory. I love you so much, pretty lady!

To Dr. Greene, thank you for opening my mind and heart to this qualitative approach. This study has allowed me to deal with the pain and continue my journey in the doctoral program. I was struggling after my mom passed to find a way to honor her and realized you laid the foundation. You opened your heart and showed us how to embrace and use our research to make changes. I admire your writing style, fiery passion, and honesty. Thank you for taking the time to believe in my dreams and helping me achieve them. In life were come across so many people, however, there are those who stand out because they make you stop and reflect. You made me stop and reflect, which allowed me to transform into the critical thinking scholar I have become. This piece has helped me in such a dark time, it has given me purpose, and kept my mind focused on finishing my doctoral journey. But most importantly writing this piece allowed me to release the pain and cope. While I cried with every word I typed it allowed me to process and impact the lives of others through this research lens. Keep lighting the fire for qualitative research.

To Dr. Sughrue, thank you for believing in my dreams and always providing advice and assistance. Your door was always open to listen and aid me in making my doctoral dream become a reality. Even though I know at times you thought I was insane for adding so much to my plate such as becoming the first doctoral student to want a double concentration. Nevertheless, you took the time to hear my dreams and create a path for me to pursue. Anytime I had an APA crisis or assignment question you always were there to support me. When I made the shift to motherhood and higher education you always provided encouragement and positivity. I appreciate you believing in my mother's dream, that her daughter could become a 
doctor. While this program is hard and at times I thought about just quitting because of the pain I was suffering in silence, you reminded me to keep working and that one day it would all be worth it. I know because of your guidance that one day I will make it and become my mother's dream, and I promise I will cry that entire day. Thank you for being a positive light in higher education, please keep captivating and supporting future educational leaders.

To Dr. Aydin, thank you for believing in me and pushing me to publish. You have always encouraged me to put my work out there and achieve. I am grateful for the opportunities you have provided me. Publishing is no easy feat however you always stressed the importance of future endeavors. When I expressed my desire to commemorate my mother with this piece, you encouraged me to pursue this. Your belief in me has allowed me to gain my confidence as a doctoral student and continue on this path. Like you always say, of course, I will get some "permanent head damage" but I have to "publish or I will perish". The beautiful thing is that this study will never perish and neither with the memory of my mom. Thank you for the encouragement and support! Keep impacting students and pushing them to be their best!

\section{References}

Almulla, H. A., \& Lewis, F. M. (2020). Losing her: Children's reported concerns in the first 6 months of their mother's breast cancer diagnosis. Cancer nursing, 43(6), 514-520. https://doi.org/10.1097/NCC.0000000000000763

Chang, H. (2008). Autoethnography as method. Left Coast Publishing.

Charmaz, K. (2005). Grounded theory in the 21st century: A qualitative method for advancing social justice research. Handbook of qualitative research, 3, 507-535.

Charmaz, K. (2006). Constructing grounded theory: A practical guide through qualitative analysis. Sage.

Charmaz, K. (2014). Constructing grounded theory (2nd ed.). Sage.

Creswell, J. W. (2018). Qualitative inquiry and research design: Choosing among five approaches (4th ed.). Sage.

Davey, M., Gulish, L., Askew, J., Godette, K., \& Childs, N. (2005). Adolescents coping with mom's breast cancer: developing family intervention programs. Journal of Marital \& Family Therapy, 31(2), 247-58. https://doi:10.1111/j.1752-0606. 2005.tb01558.x

Fisher, C. L., Wolf, B. M., Fowler, C., \& Canzona, M. R. (2017). Experiences of "openness" between mothers and daughters during breast cancer: Implications for coping and healthy outcomes. Psycho-oncology, 26(11), 1872-1880. https://doi.org/10.1002/pon.4253

Garrard, E. D., Fennell, K. M., \& Wilson, C. (2017). We're completely back to normal, but I'd say it's a new normal: A qualitative exploration of adaptive functioning in rural families following a parental cancer diagnosis. Supportive Care in Cancer, 25(11), 3561-3568. https://doi.org/10.1007/s00520-017-3785-6

Greenspan, M. (2003). Healing through the dark emotions: The wisdom of grief, fear, and despair. Shambhala.

Hedtke, L. (2014). Creating stories of hope: A narrative approach to illness, death, and grief. Australian \& New Zealand Journal of Family Therapy, 35, 4-19.

Holst-Hansson, A., Idvall, E., Bolmsjö, I., \& Wennick, A. (2017). Hoping to reach a safe havenSwedish families' lived experience when a family member is diagnosed with breast cancer. European Journal of Oncology Nursing, 31, 52-58. https://doi.org/10.1016/j.ejon.2017.10.003

Kentor, R. A., \& Kaplow, J. B. (2020). Supporting children and adolescents following parental bereavement: Guidance for health-care professionals. The Lancet Child \& Adolescent Health, 4(12), 889-898. https://doi.org/10.1016/S2352-4642(20)30184-X 
Khanjari, S., \& Mianji, M. (2020). Impact of coping skills training on the quality of life among the daughters of mothers with breast cancer. International Journal of Community Based Nursing \& Midwifery, 8(4), 333-344. https://doi.org/10.30476/ijcbnm.2020.83048.1132

Neimeyer, R. A. (1999). Narrative strategies in grief therapy. Journal of Constructivist Psychology, 12(1), 65-85.

Neimeyer, R. A. (2010). Reconstructing the continuing bond: A constructivist approach to grief therapy. Studies in Meaning, 4(1), 65-91.

Phillips, F. (2015). The experience of adolescents who have a parent with advanced cancer: A phenomenological inquiry. Palliative \& Supportive Care, 13(4), 1057-1069. https://doi.org/10.1017/S1478951514001023

Phillips, F., \& Lewis, F. M. (2015). The adolescent's experience when a parent has advanced cancer: A qualitative inquiry. Palliative Medicine, 29(9), 851-858. https://doi.org/10.1177/0269216315578989

Pickert, K. (2019). Why the women most likely to die of breast cancer have gotten the least attention. TIME. https://time.com/5689570/metastatic-breast-cancer-research-treatment/

Spry, T. (2012). Performative autoethnography: Critical embodiments and possibilities. In N. D. Denzin and Y. S. Lincoln (Eds.), Collecting and interpreting qualitative materials (4th ed., pp. 213-244).

Stiffler, D., Barada, B., Hosei, B., \& Haase, J. (2008). When Mom has breast cancer: Adolescent daughters' experiences of being parented. Oncology Nursing Forum, 35(6), 933-940.

\section{Notes on Contributor}

Alyssa Sanabria is a doctoral student in the Department of Curriculum, Instruction, and Culture at Florida Gulf Coast University, USA. Her scholarship focuses on multicultural education, diversity and inclusion, human rights, special education, post-secondary transition programs, and behavioral studies. She has taught students with emotional behavioral disorders (EBD) for seven years and is now teaching undergraduate courses within the post-secondary program at Florida Gulf Coast University. Recently, she has transitioned from the local school district to Florida Gulf Coast University and is serving as a Program Coordinator for the Soaring Eagle Academy serving students with intellectual disabilities within post-secondary education. ORCID ID: https://orcid.org/0000-0002-2686-3707 